\title{
MAPAS CONCEITUAIS E O ENSINO DA EDUCAÇÃO AMBIENTAL CRÍTICA EM UMA AULA DE CAMPO NA ESCOLA
}

\author{
Lilia Aparecida Oliveira ${ }^{1}$ \\ Plauto Simão De-Carvalho² \\ Sabrina Couto Miranda ${ }^{3}$ \\ Marcelo Duarte Porto 4
}

Resumo: A abordagem da Educação Ambiental Crítica possibilita associar questões socioeconômicas e ambientais discutindo aspectos que afetam o ser humano. Os mapas conceituais permitem verificar como o conhecimento está organizado na estrutura cognitiva do aprendiz. Considerando estas abordagens, o objetivo deste estudo foi trabalhar temáticas ambientais com alunos do $3^{\circ}$ ano do ensino médio com enfoque no bioma Cerrado em uma aula de campo (trilha) por meio da construção de mapas conceituais antes e depois desta atividade. A atividade foi desenvolvida em três fases: construção de mapa conceitual para identificar os conhecimentos prévios, realização de uma aula de campo e discussão sobre ações antrópicas e construção de outro mapa conceitual para verificar se houve evolução dos conceitos estudados. A utilização de estratégia didática por meio da construção de mapas conceituais pelos estudantes antes e depois da aula de campo constituiu uma ferramenta importante para observar os conhecimentos prévios dos alunos em relação aos temas que foram abordados nesta prática.

Palavras-chave: Cerrado; Meio ambiente; Aprendizagem Significativa; Ensino de Ciências.

\footnotetext{
1 Mestre pelo Programa Mestrado Profissional em Ensino de Ciências (PPEC). E-mail: lilia.oliveirapa@gmail.com

2 PPEC/Universidade Estadual de Goiás. E-mail: plauto.carvalho@ueg.br

3 PPEC/Universidade Estadual de Goiás. E-mail: sabrina.miranda@ueg.br

${ }^{4}$ PPEC/Universidade Estadual de Goiás. E-mail: marcelo.porto@ueg.br
} 


\section{Introdução}

A questão ambiental é um tema que precisa estar em constante discussão e transformação em sala de aula. Isto porque a formação de uma população crítica e transformadora, ciente do papel da cidadania que cada um deve exercer na sociedade atual (LIMA, 2009) resulta de um processo pedagogicamente complexo e exigente para o professor (ABREU; MIRANDA; DE-CARVALHO, 2019). Portanto, o tempo destinado ao planejamento escolar torna-se especialmente importante para o ensino da Educação Ambiental (EA) de modo a possibilitar ao professor tempo para dedicar-se na busca por metodologias que possam despertar o interesse do aluno no tema a ser discutido (DIAS; LEAL; JUNIOR, 2016; OLIVEIRA et al., 2019).

Os Parâmetros Curriculares Nacionais (PCNs), no tópico Ensinar e aprender em Educação Ambiental, reforça a concepção de que uma consciência ambiental somente será concebida quando o aprendiz conseguir atribuir significado àquilo que aprende. Nestas circunstâncias, é possível oportunizar ao estudante momentos em que se pode aplicar habilidades, competências e novos conceitos por meio da ligação que o estudante estabelece entre o que aprende e o que já conhece (BRASIL, 1997). Esta é basicamente a perspectiva pedagógica da Aprendizagem Significativa de Ausubel. Uma estratégia didática para potencialmente alcançar este processo de ensino-aprendizagem é o uso de mapas conceituais.

Mapas conceituais constituem diagramas estruturando hierarquicamente um conjunto de conceitos e suas possíveis relações. Este instrumento é capaz de possibilitar a estruturação do conhecimento e visualização de como este conhecimento está organizado na estrutura cognitiva do aprendiz (MOREIRA, 2006; TAVARES, 2007). Considerando a demanda particularmente enfatizada atualmente para um ensino com tendência à personalização, ativo, significativo e motivacional, torna-se imprescindível o uso de metodologias diversificadas em sala de aula. Estes processos pedagógicos podem ressignificar a prática docente (SANTOS; DE-CARVALHO, 2018). Contudo, qualquer que seja a estratégia didática aplicada, a perspectiva pedagógica deve estar intencionalmente ajustada às condições da estrutura cognitiva do aluno. Acessar esta estrutura é, portanto, uma necessidade fundamental para a eficiência do processo de ensino-aprendizagem. Os mapas conceituais podem facilitar este processo.

Deste modo, a forma de como a sala de aula ainda é concebida na maioria das escolas tradicionais não motiva os alunos, muito menos favorece $o$ conteúdo ou o debate. Isto porque o mundo parece se transformar mais rapidamente que a escola, seja nas tecnologias, relações sociais e políticas (SANTOS; CHIAPETTI, 2011). Portanto, o professor atualmente não é a única fonte de conhecimento aos alunos, mas não significa que a docência se tornou desnecessária, o professor precisa evitar que o aluno apenas memorize os conteúdos de forma arbitrária. É importante conduzir naturalmente o aluno a entender, por si só, como o seu próprio conhecimento está estruturado, 
permitindo-o relacionar conceitos que considera relevantes sobre um determinado tema. A partir daí, basta motivá-los a consolidar cada vez mais estes conceitos e suas relações, bem como aumentar a complexidade, reorganizando as relações hierárquicas destes conceitos em sua estrutura cognitiva.

Enquanto educadores, os autores deste estudo se propuseram no planejamento de uma prática baseada em uma trilha monitorada numa área do Cerrado goiano na perspectiva da aprendizagem significativa. Nesta ocasião, participaram alunos de uma turma do $3^{\circ}$ ano do Ensino Médio que foram motivados a observarem ações antrópicas e consequências ao meio ambiente em uma área de Cerrado no distrito de Itaguaçu (Goiás). Utilizamos mapas conceituais construídos pelos alunos como método de verificação dos conceitos trabalhos e sua complexidade de relações entre estes conceitos que envolveram a temática ambiental abordada nesta aula de campo.

\section{Uma Abordagem do Cerrado Goiano no Ensino de Ciências e Biologia}

Cerrado refere-se à savanas brasileiras que representam o segundo maior bioma da América do Sul com uma área original de aproximadamente 2 milhões de quilômetros quadrados, perdendo somente para o bioma amazônico em extensão (KLINK; MACHADO, 2005). Estimativas indicam que restam apenas $20 \%$ da vegetação original e que apenas $6,2 \%$ do bioma está incluída em áreas protegidas (MYERS et al., 2000). A importância do Cerrado tem visibilidade internacional e estudos apontam que 1,5\% de toda a diversidade de plantas endêmicas do mundo está em áreas de Cerrado, considerado uma das 25 áreas no planeta prioritárias para conservação por conta de sua alta diversidade biológica e ameaças antrópicas (hotspots) (MYERS et al., 2000). Este conhecimento sobre a biodiversidade do Cerrado é um dos importantes conceitos que devem ser trabalhados no ensino de Educação Ambiental (EA).

A presença do fogo parece ter contribuído para a evolução do bioma (SIMON et al., 2009) e estudos apontam que a ocorrência de fogo entre 3 e 10 anos seria natural no Cerrado (HOFFMANN, 1999). Outros estudos sugerem que a proteção do fogo, por sua vez, favorece o incremento de elementos lenhosos influenciando na estrutura da vegetação (MIRANDA; JÚNIOR; DECARVALHO, 2013). Contudo, queimadas anuais podem resultar em alta mortalidade de plantas, especialmente indivíduos lenhosos além de contribuir negativamente na estrutura da vegetação do Cerrado (MEDEIROS; MIRANDA, 2005; MIRANDA; DE-CARVALHO; RIBON, 2019). Deste modo, na EA pode-se contextualizar o fogo natural como sendo importante para o Cerrado. Contudo, ações humanas o intensificam, tanto em frequência e intensidade (MIRANDA et al., 2018). 


\section{A Educação Ambiental no Cotidiano Escolar}

A Educação Ambiental (EA) no Brasil passou a ser mais discutida na década de 90 quando os problemas ambientais tomaram dimensões maiores: "aumento do desmatamento da Amazônia, aumento da emissão de CFC's, chuva ácida provocada pelas substâncias tóxicas provenientes da poluição atmosférica, intensificação das mudanças climáticas e do efeito estufa, enfim a sociedade civil cobrava providências para esses problemas (ABREU; MIRANDA; DE-CARVALHO, 2019; LIMA, 2009; MINISTÉRIO DA EDUCAÇÃO, 2007)

Foi em meio a esse cenário caótico, durante o governo de Fernando Henrique que foi criada a lei 9795/99 em abril de 1999, que trata da Educação Ambiental (Política Nacional da Educação Ambiental) (BRASIL, 1999). A EA deve se desenvolver em ambientes formais e não formais e criar postura epistemológica, que leve o ser humano a desenvolver uma postura crítica e refletir sobre as mudanças que ocorrem no meio social por meio do desenvolvimento de um ser ecológico (MIRANDA; ABREU; DE-CARVALHO, 2016).

Os profissionais da educação, através da lei citada acima, precisam trazer as questões ambientais para o cotidiano escolar e tratar dessas questões presentes nas principais mídias de comunicação. $O$ intuito é formar um aluno, não apenas consciente ecologicamente, mas capaz de promover transformações no local que ele circula (FREIRE, 1996). Esta concepção pedagógica pode ser associada ao desenvolvimento sustentável que surgiu com o intuito de moldar novos hábitos para a sociedade para não comprometer as gerações futuras. Neste sentido, é necessário a mudança de hábitos das pessoas, em relação ao meio ambiente, como por exemplo, a diminuição do consumismo (RODRIGUES et al., 2019). A função do desenvolvimento sustentável e da EA é construir a demanda por adoção de uma postura voltada à sustentabilidade, mas acima de tudo, pela postura crítica que alimente a mobilização social em detrimento aos movimentos que acentuem a pobreza e o consumo desenfreado e ao encontro de uma sociedade mais igualitária (BIGLIARDI; CRUZ, 2007).

É através das ações desenvolvidas na escola que se poderá abrir espaço para reflexão e transformação de uma sociedade crítica e transformadora que levam à tomada de decisão frente à crise civilizatória e ambiental. Deste modo, a transformação social que emerge do debate ambiental pode contribuir na superação da desigualdade social, das injustiças ambientais, da excessiva apropriação capitalista e funcionalista dos recursos naturais e da própria humanidade. Ou seja, a Educação Ambiental possibilita uma mudança de paradigma que implica tanto uma revolução científica quanto política (SORRENTINO, 2001).

Para tanto, a EA na escola deve estar inserida em todas as disciplinas não exclusivamente na Biologia e Geografia. Portanto, existe a demanda por todas as áreas do conhecimento para se discutir possíveis soluções para as

revista brasileira educação ambiental 
consequências da degradação socioambiental, mas é por meio da educação que poderemos ter uma mudança do cenário presente em decorrência da crise socioambiental (GUIMARÃES; VASCONCELLOS, 2006).

\section{A Educação Ambiental crítica e as contribuições de Paulo Freire}

A macrotendência Educação Ambiental Crítica, também conhecida como transformadora, popular, emancipatória e dialógica, possui ênfase na análise crítica dos fundamentos que proporcionam a dominação do ser humano e acumulação do Capital (LAYRARGUES; DA COSTA LIMA, 2014). A EA Crítica possui politização da Educação Ambiental por meio de análises sociológicas, políticas, sociologia da educação, com teor crítico e integrador (GUIMARÃES, 2004), apresenta concepção alinhada ao socioambientalismo, crítico-emancipatório (LIMA, 2009), com abordagem social marcante (LAYRARGUES, 2004), consolidando como instrumento de crítica à crise civilizatória atual (BIGLIARDI; CRUZ, 2007).

Portanto, o objetivo político-pedagógico é de transformar a sociedade atual numa sociedade pensante, capaz de apontar soluções aos problemas ambientais, crítica dos problemas ao seu redor e não apenas conscientização dos problemas. No entanto, para o desenvolvimento da EA crítica é necessário que a população esteja cientificamente alfabetizada diante dos problemas ambientais (GUIMARÃES; VASCONCELLOS, 2006). Deste modo, a EA, na vertente crítica, se difere por defender a construção de uma sociedade crítica, com capacidade de refletir criticar e transformar.

Assim, há um forte viés sociológico e político, e no debate conceitoschave como cidadania, democracia, participação, emancipação, conflito, justiça ambiental e transformação social são introduzidos. A EA Crítica está crescendo nas discussões, mas ainda se encontra muito restrita ao âmbito das pósgraduações (LAYRARGUES; DA COSTA LIMA, 2014). A Educação Ambiental na perspectiva Crítica consolida-se pela prática social intencional orientada para propiciar ao estudante condições cognitivas para que, por meio de ações coletivas, busquem superar o modelo de sociedade atual, pautado nas formas capitalistas de dominação e exploração do trabalho e suas consequentes relações com a natureza (ARNALDO; SANTANA, 2018).

Quando se fala em EA Crítica não há como não mencionar Paulo Freire como pedagogo que contribuiu para a ideologia da mesma, por meio do livro "A Pedagogia do Oprimido" (FREIRE, 1987). No livro citado, Paulo Freire descreve sobre o que ele chamou de "educação bancária", onde o professor deposita conteúdos e os educandos simplesmente os recebe de forma alienada, passiva. A educação bancária é aquela onde o educador só deposita conteúdos, e os educandos se comportam como "vasilhas", quanto mais cheias, melhores serão, onde os educadores são os que enchem esses recipientes, quanto mais cheio esse tiver melhor está a educação (FREIRE, 1987). 
Nesse sentido, quando Freire compara os educandos a vasilhas que se enchem, ele critica a educação que apenas transmite conhecimento e não forma uma população crítica, capaz de debater assuntos relacionados a todos os setores da sociedade. Ainda sobre Freire, ele continua "Eis aí a concepção "bancária" da educação, em que a única margem de ação que se oferece aos educandos é a de receberem os depósitos, guardá-los e arquivá-los." (FREIRE, 1987).

A EA crítica propõe os mesmos ideários que Freire, a formação crítica e libertadora, onde os sujeitos sejam capazes de discutir e apontar soluções, que atuem como ser pensante e não apenas "vasilhas que vão enchendo". Ao fazer essa relação entre a pedagogia defendida por Freire e a ideologia da EA crítica fica implícito a relação entre elas. Deste modo, procura-se propor uma mudança na concepção de Educação Ambiental existente até então. Neste caso, uma educação efetivamente autocrítica (LOUREIRO; LAYRARGUES, 2013)

\section{Ausubel, a aprendizagem significativa, o uso de mapas conceituais e a Educação Ambiental}

$\mathrm{Na}$ aprendizagem significativa, 0 processo de aquisição do conhecimento é entendido por meio da qual uma nova informação (um novo conhecimento) se relaciona de maneira não arbitrária e substantiva (não-literal) à estrutura cognitiva do aprendiz. Ou seja, na concepção da aprendizagem significativa, o desenvolvimento do conhecimento ocorre pela organização da estrutura cognitiva de modo que o significado lógico do material de aprendizagem se transforma em significado psicológico para o sujeito (MOREIRA, 2011a, 2011b).

Nesse sentido, por meio da perspectiva de Ausubel, a aprendizagem significativa ocorre quando o aluno compreende o que the foi ensinado ao fazer relações com o conhecimento que o aluno já possui, também chamado de conhecimento prévio. Este relacionamento não é com qualquer aspecto da estrutura cognitiva, mas sim com conhecimentos especificamente relevantes, os quais Ausubel denominou subsunçores. Portanto, o conhecimento prévio do aluno é essencial para que a aprendizagem significativa ocorra (MOREIRA, 2011a, 2011b).

É o professor orientador que deve proporcionar atividades que tenham relação com o dia a dia do aluno para que possa haver ancoragem. Cabe, no entanto, ao professor promover problemas e desafios, de modo que o aluno veja sentido em participar da aula e assim promover a aprendizagem significativa. Contudo, caso o aluno receba o conteúdo de forma arbitrária, apenas ocorrerá a memorização. A aprendizagem mecânica acontece quando os conceitos aprendidos não se incorporam ao conhecimento prévio que o aluno já possui, nesse caso ocorre a memorização apenas (OLIVEIRA; FROTA, 2012). 
Para evitar a aprendizagem mecânica o professor precisa inovar as estratégias utilizadas em sala de aula. Os mapas conceituais podem ser uma ferramenta essencial para promover a aprendizagem significativa e evitar a aprendizagem mecânica. Isto porque a aprendizagem mecânica ocorre quando o aluno recebe um novo conhecimento e não estabelece conexão com os conhecimentos prévios. Ou seja, o aluno recebe algum conhecimento, e até consegue memoriza-lo de alguma forma parcial, mas não consegue relacionálo aos conhecimentos contidos nas estruturas cognitivas anteriores. A proposta dos mapas conceituais é justamente organizar conceitos e relações entre eles (MOREIRA, 2006). Portanto, o uso de mapas conceituais pode auxiliar para uma aprendizagem significativa.

Os mapas conceituais são representações gráficas que possibilitam uma melhor organização e representação do conhecimento. Eles incluem conceitos, geralmente dentro de círculos ou quadros de alguma espécie, e relações entre conceitos, que são indicadas por linhas que os interligam (NOVAK; GOWIN, 1996; TAVARES, 2007).

Além dos professores e alunos trabalharem com ideias chaves nos mapas conceituas, a linguagem utilizada pode ser mais acessível aos alunos, uma vez que os mesmos têm hábito de reclamar do vocabulário complicado de biologia. A terminologia técnica pode afastar o interesse do aluno. Contudo, caso ele entenda a natureza do conhecimento ensinado, a lógica e as relações mais abrangentes relacionadas à estes conceitos, a aquisição da terminologia técnica pode ser encarada positivamente e progressivamente.

Portanto, o professor que opta em inovar as metodologias em sala de aula para promover a aprendizagem significativa pode evitar a aprendizagem mecânica. Neste caso, o professor interessado nesta proposta, deve levar em consideração os conhecimentos prévios que os alunos já possuem. Os mapas conceituais são ótimas ferramentas para introduzir um conhecimento. Contudo é fundamental que ele tenha ligação com os conhecimentos que os estudantes possuem. Portanto, deve haver uma estratégia pedagógica que possibilite uma ambiência na qual estes conhecimentos prévios emerjam tanto para o professor quanto para o aluno.

O trabalho de Educação Ambiental deve ser desenvolvido a fim de ajudar os alunos a construírem uma consciência global das questões relativas ao meio para que possam assumir posições afinadas com os valores referentes à sua proteção e melhoria. Para isso, é importante que possam atribuir significado àquilo que aprendem sobre a questão ambiental (BRASIL. SECRETARIA DE EDUCAÇÃO FUNDAMENTAL, 1998). De acordo os PCN's o papel da EA é de atribuir valores ambientais aos alunos por meio de atividades relacionadas as questões locais. Para os PCN's "A perspectiva ambiental oferece instrumentos para que o aluno possa compreender problemas que afetam a sua vida, a de sua comunidade, a de seu país e a do planeta". O professor pode utilizar os problemas ambientais locais para promover 
discussões, por pertencer ao cotidiano do aluno despertará o interesse dos estudantes.

Nesse sentido, a realidade local é uma ótima oportunidade a ser explorada pelo professor o que leva ao interesse e participação do aluno, por se tratar de conteúdos relacionados à sua vivência, fazendo relação com o conhecimento que já possui. Neste contexto, planejamos a importância pedagógica que uma aula de campo pode ter, em uma trilha interpretativa, numa região rural, campo de plantações de cana de açúcar, nas fazendas localizadas aos arredores de Itaguaçu.

\section{Material e Métodos}

O projeto foi desenvolvido em 3 fases, com a participação da $3^{a}$ série do Ensino Médio, do turno matutino, em uma escola da rede pública de ensino, situada no município de São Simão, Goiás. A metodologia usada teve abordagem qualitativa com utilização de mapas conceituais e observação das informações contidas neles.

A turma foi composta por 12 alunos, com idade entre 16 e 18 anos, onde eles mostraram interesse em participar da atividade sugerida. Duas etapas foram realizadas na unidade escolar e uma foi a trilha, fora da escola.

1) A primeira atividade foi desenvolvida na escola, e teve duração de uma aula, 50 minutos. Primeiramente, foi exposto um vídeo de 12 minutos com utilização de projetor de imagens, ele falava da construção de mapas conceituas. Em seguida foi sugerida à turma que fizesse a produção individual de mapa conceitual cujo tema era Cerrado.

2) $\mathrm{Na}$ aula seguinte foi a realização da trilha monitorada. No dia anterior ao passeio sugeriu-se que os alunos viessem de trajes adequados, inclusive de bonés ou chapéus, que utilizassem filtro solar e que levassem água.

3) $\mathrm{Na}$ aula do dia seguinte, os alunos que participaram da atividade anterior, elaboraram outro mapa conceitual, possibilitando assim a evolução no aprofundamento do assunto.

\section{Resultados e Discussão}

Após aprofundamento teórico por meio de leitura minuciosa foi possível a elaboração de um mapa conceitual que contempla os principais autores, que no nosso ponto de vista, apresentam fundamentação teórica e prática na temática de EA crítica e que podem estar associados à uma postura pedagógica orientada na perspectiva da aprendizagem significativa ausubeliana (Figura 1). 


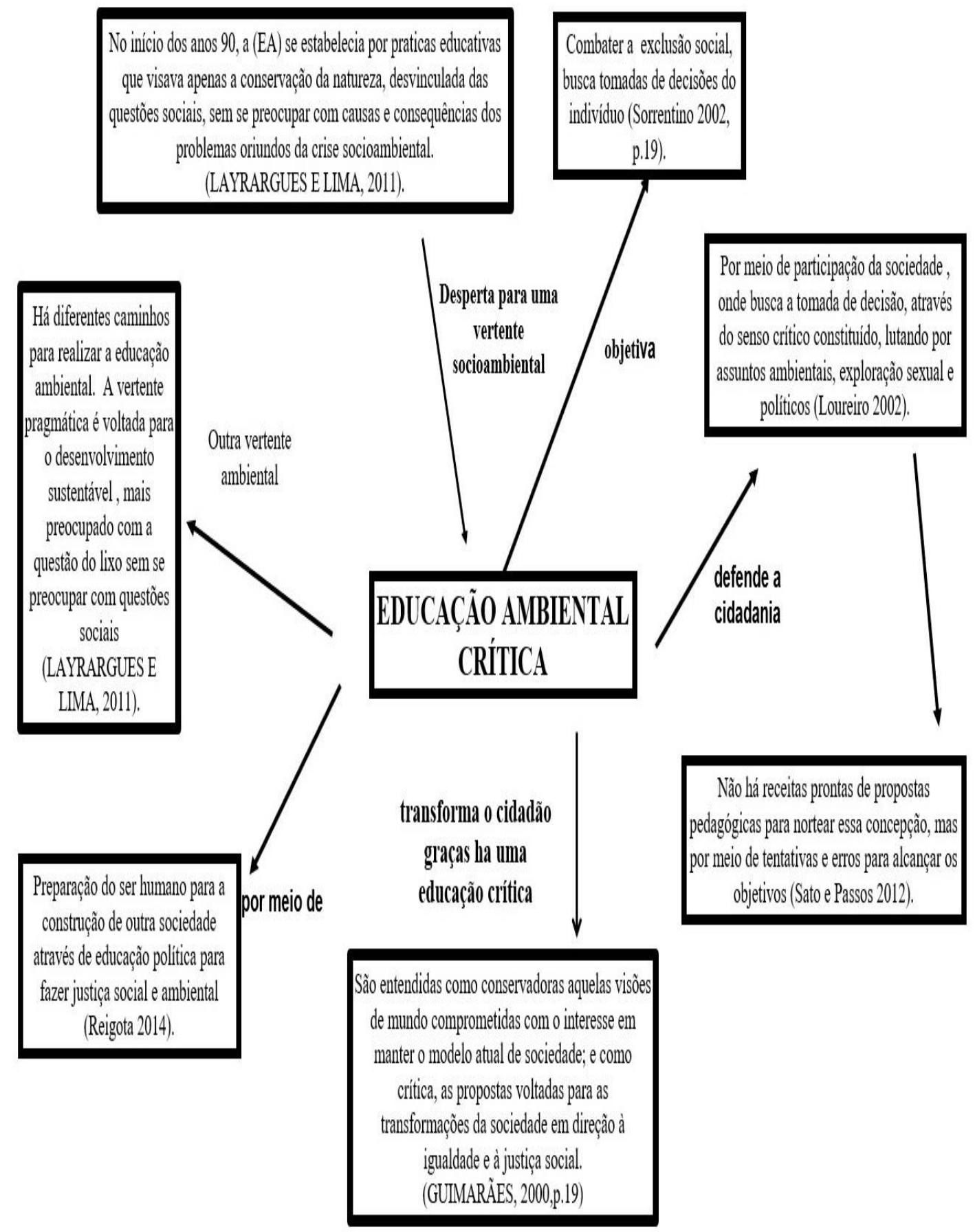

Figura 1: Mapa conceitual sobre Educação Ambiental Crítica, importantes conceitos e autores relacionados. Fonte: próprios autores. 
2009). O professor deve buscar meios para inovar sua atuação em sala de aula, o aluno do século XXI é diferente dos estudantes do século passado. $O$ aluno de antes tinha o papel apenas de aprender o que era ensinado, esse modelo de estudante está se esgotando (SANTOS; DE-CARVALHO, 2018). Nesse sentido, a metodologia utilizada foi no sentido de aproximar o aluno das questões pertinentes ao ambiente de modo que o aluno assuma uma postura ativa.

Durante a realização da primeira atividade, iniciamos a aula perguntando se eles conheciam mapas conceituais, eles disseram que já haviam trabalhado com essa metodologia na disciplina de geografia. Nessa aula estavam presentes 10 dos 12 alunos que compõem a turma.

Apresentamos a atividade a ser desenvolvida sobre construção de mapas conceituais antes e depois da trilha, todos ficaram muito entusiasmados e sugeriram que o percurso da trilha fosse feito de bicicleta. Este processo foi importante para que o professor pudesse fundamentar seu trabalho conforme as necessidades individuais de seus alunos uma vez que cada um pode construir o seu mapa de acordo com as suas convicções, considerando sempre uma estratégia lúdica, o momento emocional e as ansiedades do aluno no momento da atividade pedagógica (MORAES; VARELA, 2007; SANTOS; DECARVALHO; MIRANDA, 2019).

A utilização de mapas conceituais foi um recurso metodológico capaz de verificar os conhecimentos que os alunos consideravam relevantes para a temática ambiental em questão. Os mapas também podem ser eficientes em processos avaliativos de diferentes conteúdos, considerado um facilitador na aprendizagem significativa sobre vários aspectos (SOUZA; BORUCHOVITCH, 2010). Para que esta intencionalidade pedagógica tenha o efeito esperado, é fundamental ensinar para o aluno como organizar seu conhecimento, especialmente sobre como construir um mapa conceitual. Para tanto, os alunos foram conduzidos ao laboratório de informática a fim de assistir a um vídeo sobre mapas conceituais.

$\mathrm{Na}$ ocasião, apenas 8 alunos fizeram a atividade proposta. Após análise de cada trabalho foi possível concluir que o conhecimento de todos os alunos sobre Cerrado era em torno apenas da fauna e flora, clima e solo. Os trabalhos apresentaram nomes de plantas e animais e característica da vegetação. Um aluno trouxe as queimadas como benefício. Logo abaixo observa-se a Figura 1, com alguns trabalhos desenvolvidos pelos alunos a, b, c, da escola já citada no trabalho (Figura 2). 


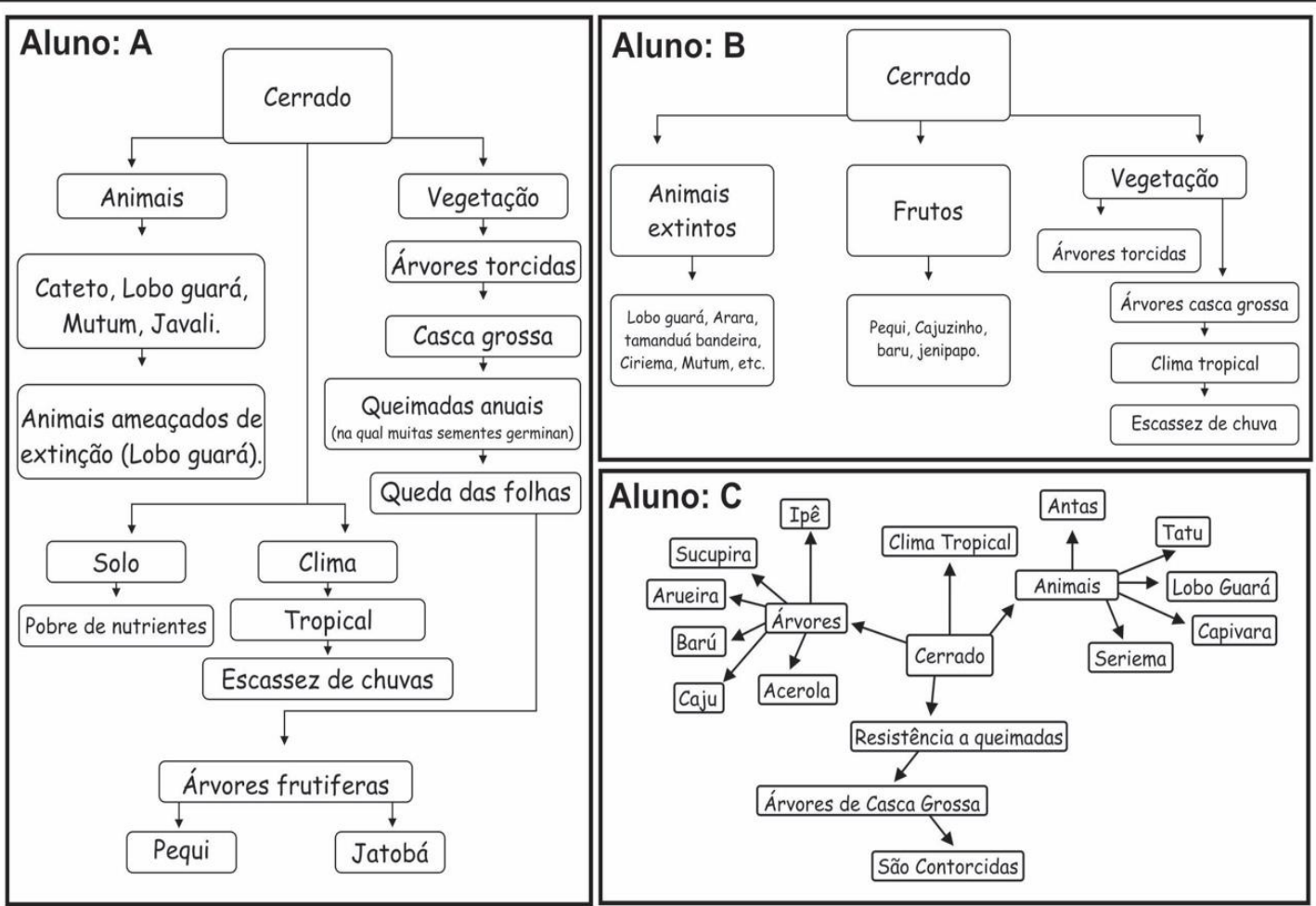

Figura 1 - Fonte: Alunos A, B, C, estudante do Colégio Estadual Presidente Castelo Branco, mapas conceituais elaborados antes da aula de campo (trilha).
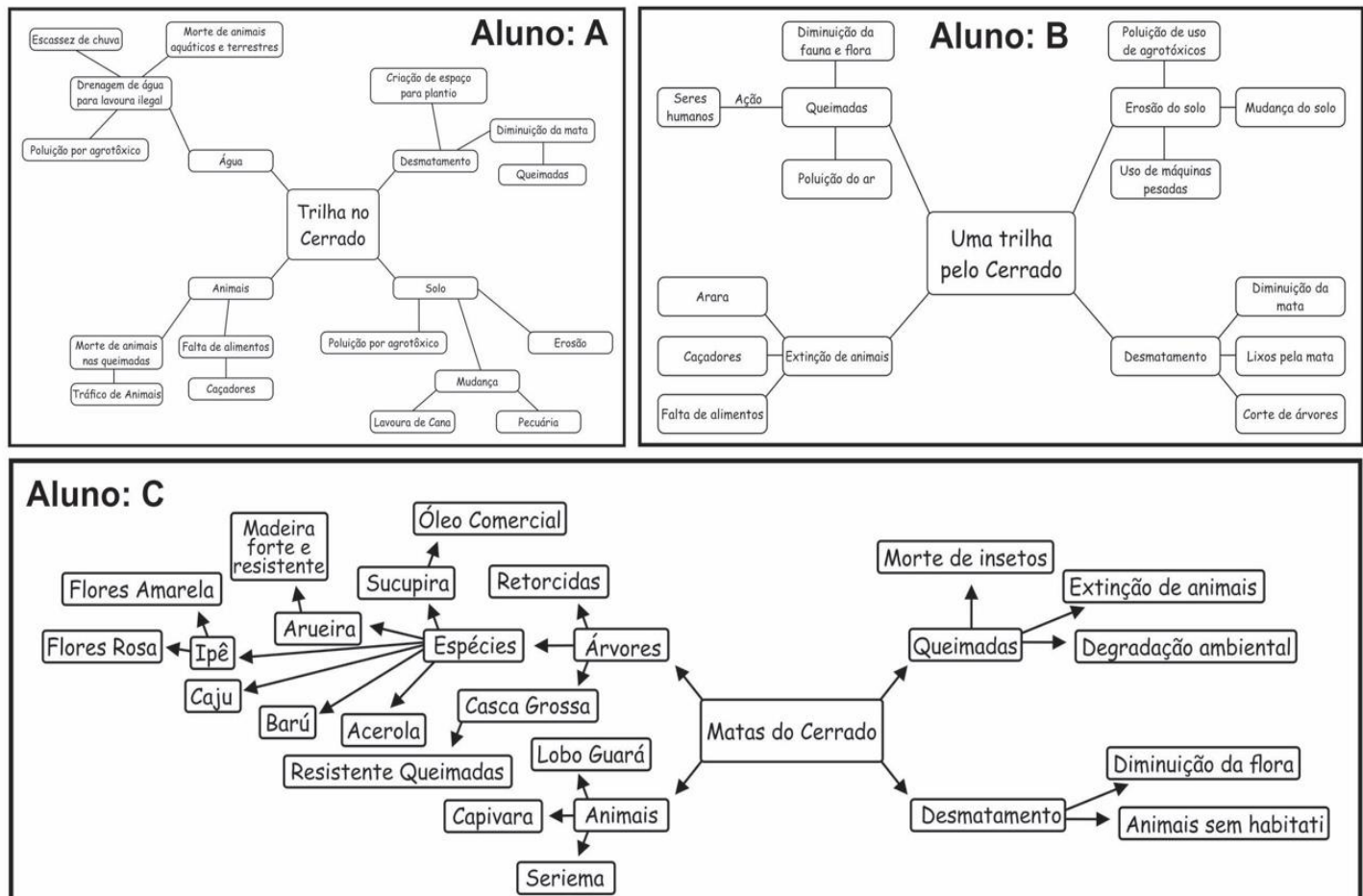

Figura 2 - Fonte: Alunos A, B, C, estudante do Colégio Estadual Presidente Castelo Branco, mapas conceituais elaborados após da aula de campo (trilha).

Revbea, São Paulo, V. 14, № 3: 220-237, 2019. 
A observação dos conhecimentos prévios do aluno foi uma ótima oportunidade para o professor expressar meios de sanar as possíveis dúvidas e através de conceitos gerais aprofundar num determinado assunto. A partir do reconhecimento dos conceitos presentes na estrutura cognitiva do aluno, foi possível repensar, mesmo que no momento do ensino em sala de aula, os melhores caminhos por onde iniciar a relação destes com os novos conceitos sobre o tema proposto (OLIVEIRA; FROTA, 2012). Portanto, foi uma ferramenta didática facilitadora para a consolidar a intencionalidade pedagógica orientada para a aprendizagem significativa.

Nesse sentido, através dos conhecimentos já existentes foi possível ao professor ter noção de como abordar o novo assunto. $O$ uso de mapas conceituais pode ser uma metodologia ativa. Isto porque 0 aluno pode perceber suas dificuldades sobre o tema, ou reconhecendo que poderia ter feito novas relações entre conceitos, ou que o entendimento prévio sobre um determinado conceito não estava bem delineado anteriormente. Neste momento, conscientemente o aluno poderá procurar subsídios de forma a suprir lacuna e a construir um novo mapa mais elaborado e complexo, ou seja, demonstrando a aprendizagem significativa desenvolvida em sua estrutura cognitiva (OLIVEIRA; FROTA, 2012).

No dia seguinte foi a realizada a trilha ecológica. Participaram da mesma 9 alunos. Os demais alunos não compareceram à aula. Saímos da escola de bicicleta e percorremos um trajeto de 2 quilômetros até chegar à área a ser observada. A escolha pela área em questão é por se tratar de uma plantação de cana de açúcar, anteriormente era constituída por fazendas de pastagens. Havia trechos de área de reserva, mas recentemente foi totalmente devastada por queimadas durante a estação seca.

Ao chegar ao local, os alunos mostraram-se totalmente interessados em saber sobre as ações antrópicas no cerrado, discutimos sobre o processo de desmatamento para introdução de pastagens e posteriormente lavoura de cana-de-açúcar. Esta característica foi importante pois os assuntos abordados foram bem recebidos pelos alunos considerando-os relevantes e não-arbitrários em relação à temática previamente debatida em sala de aula (ARAÚJO; SILVA, 2015; MIRANDA; ABREU; DE-CARVALHO, 2016; MONTANINI; MIRANDA; DE-CARVALHO, 2019). Além disto, esta postura facilita o processo de ensino aprendizagem uma vez que a primeira condição para aprendizagem significativa diz respeito ao fato de o sujeito querer aprender (MOREIRA, 2011a). Os alunos em questão apresentavam muito interesse no conteúdo e perguntavam qual outro momento teriam outra oportunidade igual àquela em um ambiente diferente.

Ao nosso ver, o ambiente não formal contribuiu para motivar o interesse dos alunos na aquisição de conhecimento, sendo assim a escola pode promover momentos de aprendizagem em ambientes não formais principalmente ao ar livre, onde a própria natureza se encarrega de mostrar 
elementos naturais que enriquecem o aprendizado, uma vez que a disciplina em questão se tratava de Biologia, ensino de Ecologia.

Observamos também as queimadas que devastaram toda a região, a reserva protegida ficou totalmente destruída após o fogo, discutimos sobre os prejuízos causados à fauna e a flora. Nesse momento, houve muito questionamento e perguntas pelos alunos. A aula em espaços formais não oferece os mesmos mecanismos de ensino presentes em uma aula de campo. O ensino mostrando a realidade visual para o aluno permite a aquisição de vários sentidos deste a utilização da visão, tato e olfato proporciona momentos que levam a aprendizagem. Estas vantagens pedagógicas são importantes e debatidas em estudos sobre o tema (ARAÚJO; SILVA, 2015).

Várias reflexões foram feitas a respeito das queimadas, alguns alunos tinham a noção de que queimadas são benéficas ao bioma, mas não sabiam em quais condições. Nessa ocasião, eles puderam constatar que as queimadas anuais trazem muitos prejuízos, além de financeiros aos proprietários, mas principalmente à fauna e a flora local. Estudos sobre o tema reforçam a importância de mostrar estas relações biológicas e socioeconômicas para as crianças e adolescentes em formação (MIRANDA; DE-CARVALHO; RIBON, 2019; MIRANDA; ABREU; DE-CARVALHO, 2016; MONTANINI; MIRANDA; DE-CARVALHO, 2019).

A atividade teve duração de 2 horas. Em seguida, retornamos para a escola. No dia posterior à aula de campo, em sala de aula retomamos o conteúdo de cerrado e sugeriu-se que cada aluno fizesse novamente outro mapa conceitual. Nessa última fase foi a avaliação da aprendizagem. Todos os alunos que foram à aula de campo fizeram a atividade proposta. Foi informado novamente aos alunos como se constrói um mapa conceitual e foi sugerido que o fizessem novamente, como método de avaliação. O objetivo de pedir aos alunos que fizessem dois mapas conceituais, um antes e outro após a trilha foi para observar se houve conceituação diferente sobre o tema Cerrado e verificar se houve aprendizagem significativa sobre o tema.

Pudemos verificar, ao fazer a comparação entre os mapas conceituais, e logo após esta aula de campo que houve diferença tanto para novos conceitos que foram utilizados, novas relações, estruturas mais complexas e relações mais abrangentes (Figura 2). Dessa forma, o mapa conceitual funcionou como uma ferramenta medidora do processo de aprendizagem significativa. A eficiência dos mapas conceituais para este fim tem sido bem delimitada na literatura (SOUZA; BORUCHOVITCH, 2010; TAVARES, 2007; TOALDO et al., 2018). Em nenhum dos primeiros mapas os alunos apontaram os problemas do Cerrado, mas nos últimos esses conceitos estavam presentes.

Percebemos que a maioria dos alunos não utilizou palavras de ligação nos mapas. Porém houve evolução em $100 \%$ dos trabalhos analisados. Os alunos apresentaram, posteriormente, a utilização de conceitos além de componentes da fauna e flora do Cerrado. A utilização de mapa conceitual 
como avaliação facilitou analisar o progresso no conhecimento sobre os problemas do cerrado. Acreditamos que este aprendizado foi significativo para os alunos.

Maioria dos professores utilizam teste de múltipla escolha como meio de avaliação no processo de ensino aprendizagem (NOVAK; GOWIN, 1988). Contudo, pode ocorrer uma efetiva falta de correspondência entre o que o professor pensa estar avaliando e os autênticos significados cognitivos que o estudante está utilizando (NOVAK; GOWIN, 1996).

Ao observar os mapas elaborados por cada aluno, percebe-se que houve incorporação de novos conceitos. Segundo Novak (1984 p.114) "A análise desses mapas antes e depois nos dá subsídios para concluirmos se houve aprendizagem significativa." Os primeiros mapas apresentavam menos conceitos, menos ligações e menos setas. Já nos segundos mapas conceituais, observou-se que a quantidade desses elementos aumentou significativamente e os mapas estavam mais ricos de informações. Com base nestas observações, concluímos que houve aprendizagem significativa dos conceitos estudados.

De acordo com Novak (1984 p.115) "O professor deve estar atento a possíveis alternativas hierárquicas criativas". A apresentação de novas alternativas hierárquicas entre os subsunçores observados nos mapas conceituais produzidos pelos estudantes demonstra novas organizações de conceitos que só podem ter sido produzidas por meio de uma estrutura cognitiva mais consolidada a partir da metodologia adotada. Portanto, através desses elementos é possível afirmar que houve aprendizagem significativa pela incorporação de novos conceitos e ordenação de conhecimentos prévios.

Por meio deste estudo, mostramos que é possível ajustar uma abordagem de EA na vertente crítica basicamente pela escolha de um método pedagógico mais adequado, que permita ambiência para que o debate de conhecimentos prévios, muitas vezes decorrentes de experiências do cotidiano social e cultural do estudante tome protagonismo no processo de ensinoaprendizagem. Neste sentido, o uso de mapas conceituais pode ser uma ferramenta didática valiosa para que o professor acesse abordagens mais assertivas para conduzir o estudo para uma experiência de aprendizagem que critique a realidade no qual o estudante está submetido.

Esta vertente ambiental propõe ações que intervém sobre a realidade e os problemas ambientais de cada um para superar a realidade presente no ambiente escolar. Neste sentido, é possível fugir das "armadilhas paradigmáticas" predominantes nas escolas brasileiras com o foco no professor e que não possibilitam uma abordagem crítica (GUIMARÃES, 2004). Aulas do tipo em que ocorre apenas transmissão de conteúdo, desvinculadas do cotidiano escolar, são comuns de acontecerem, mas é preciso superar essas ações. Nesse intuito, o professor precisa ousar e ir além da sala de aula (GUIMARÃES, 2004; SANTOS et al., 2019). 
Ao propor a aula de campo fica evidente o objetivo de trabalhar questões relacionadas ao meio ambiente e ao cotidiano do dia a dia do aluno, na sua forma mais natural (natureza). Ao analisar a área de plantação os alunos puderam refletir sobre a ação humana que causa queimadas, erosões e não apenas produção econômica. Essa reflexão faz parte de muitos momentos promovidos pela escola que pode ser chamada de EA crítica. Nesse sentido, o educador ambiental deve buscar a inovação do processo de ensino aprendizagem onde o ensino não se restringe apenas à transmissão de conteúdo, mas que busque um movimento coletivo e não o ensino individualizado, para formação de cidadania.

\section{Conclusões}

O mapa conceitual foi uma ótima ferramenta para observar os conhecimentos prévios dos alunos. Os alunos participantes puderam utilizar um vocabulário acessível a eles, uma vez que a construção é de própria autoria, e o professor pôde acompanhar a evolução do conhecimento. Possíveis dúvidas que surgiram ao longo das atividades puderam ser mais bem trabalhadas e debatidas considerando as ações antrópicas em áreas do Cerrado.

É por meio de atividades como estas, onde o aluno tem contato direto com o meio ambiente que a EA crítica se efetiva. Contudo, esse trabalho deve ser constante e realizado de forma coletiva na realidade escolar. Todos os professores precisam estar dispostos, a sair das quatro paredes da sala de aula e promover momentos onde 0 aluno possa perceber as mudanças ocorridas no meio ambiente que altera sua forma natural, promover debates onde o aluno possa assumir uma postura crítica e sair da alienação de apenas ouvir e guardar o conhecimento.

Os alunos tiveram ótima aceitação desse recurso, pois se comprometeram a produzir os dois mapas solicitados. Portanto, mapas conceituais foram uma ótima ferramenta que pode auxiliar o professor observar os conhecimentos prévios.

\section{Referências}

ABREU, C.R.; MIRANDA, S.C.; DE-CARVALHO, P. S. Análise das Publicações Brasilieiras sobre Educação Ambiental com Enfoque na Temática Mudanças Climáticas. Enciclopédia Biosfera, v. 16, n. 29, p. 1744-1763, 30 jun. 2019.

ARAÚJO, J. N.; SILVA, M. DE F. V. Aprendizagem significativa de botânica em ambientes naturais. Revista Amazônica de Ensino de Ciências, v. 8, n. 15, p. 100-108, 2015.

ARNALDO, M. A.; SANTANA, L. C. Políticas públicas de Educação Ambiental e processos de mediação em escolas de Ensino Fundamental. Ciência \& Educação (Bauru), v. 24, n. 3, p. 599-619, set. 2018. 
BIGLIARDI, R. V.; CRUZ, R. G. O Papel Da Educação Ambiental Frente À Crise Civilizatória Atual. Ambiente e Educação, v. 12, p. 127-141, 2007.

BRASIL. SECRETARIA DE EDUCAÇÃO FUNDAMENTAL. Parâmetros curriculares nacionais : terceiro e quarto ciclos do ensino fundamental: introdução aos parâmetros curriculares nacionais. Brasília: [s.n.].

BRASIL. Parâmetros Curriculares Nacionais: Meio Ambiente, SaúdeSecretaria de Educação Fundamental. Brasília: [s.n.].

BRASIL. Lei $n^{\circ}$ 9.795, de 27 de abril de 1999. Dispõe sobre a Educação Ambiental, institui a política nacional de Educação Ambiental e dá outras providências. Brasil Diário Oficial da União, Brasília, 28 abr., , 1999.

DIAS, L. S.; LEAL, A. C.; JUNIOR, S. C. Educação Ambiental: conceitos, metodologias e práticas. 1a Ed. ed. Tupã - SP: ANAP - Associação Amigos da Natureza da Alta Paulista, 2016.

FREIRE, P. Pedagogia do oprimido. Rio de Janeiro: Paz e Terra - (Coleção Leitura), 1987.

FREIRE, P. Pedagogia da Autonomia: Saberes necessários à prática educativa. São Paulo: Paz e Terra - (Coleção Leitura), 1996.

GUIMARÃES, M. Educação Ambiental Crítica. [s.l: s.n.].

GUIMARÃES, M.; VASCONCELLOS, M. DAS M. N. Relações entre Educação Ambiental e educação em ciências na complementaridade dos espaços formais e não formais de educação. Educar em Revista, n. 27, p. 147-162, jun. 2006.

HOFFMANN, W. A. Fire and Population Dynamics of Woody Plants in a Neotropical Savanna: Matrix Model Projections. Ecology, v. 80, n. 4, p. 13541369, jun. 1999.

KLINK, C.; MACHADO, R. A conservação do Cerrado brasileiro. Megadiversidade, v. 1, n. 1, p. 147-155, 2005.

LAYRARGUES, P. P. Identidades Da Educação Ambiental Brasileira/ Ministério do Meio Ambiente. Brasília: Ministério do Meio Ambiente - Diretoria de Educação Ambiental, 2004.

LAYRARGUES, P. P.; DA COSTA LIMA, G. F. As Macrotendências PolíticoPedagógicas da Educação Ambiental Brasileira (The brazilian environmental education macro-political-pedagogical trends). Ambiente e Sociedade, v. 17, n. 1, p. 23-40, 2014.

LIMA, G. F. D. C. Educação Ambiental crítica: do socioambientalismo às sociedades sustentáveis. Educação e Pesquisa, p. 145-163, 2009.

LOUREIRO, C. F. B.; LAYRARGUES, P. P. Ecologia política, justiça e Educação Ambiental crítica: perspectivas de aliança contra-hegemônica. Trabalho, Educação e Saúde, v. 11, n. 1, p. 53-71, 2013. 
MATOS, C. H. C. et al. Utilização de Modelos Didáticos no Ensino de Entomologia. Revista De Biologia E Ciências Da Terra, v. 9, n. 1, p. 19-23, 2009.

MEDEIROS, M. B. DE; MIRANDA, H. S. Mortalidade pós-fogo em espécies lenhosas de campo sujo submetido a três queimadas prescritas anuais. Acta Botanica Brasilica, v. 19, n. 3, p. 493-500, set. 2005.

MINISTÉRIO DA EDUCAÇÃO. Vamos cuidar do Brasil. Brasília - DF: Ministério da Educação, Coordenação Geral de Educação Ambiental: Ministério do Meio Ambiente, Departamento de Educação Ambiental : UNESCO, 2007.

MIRANDA, S. DO C. DE et al. Apontamentos sobre mundanças climáticas na agricultura brasileira. Enciclopédia Biosfera, Centro Científico Conhecer, v. 15, n. 27, p. 95-106, 2018.

MIRANDA, S. DO C. DE; DE-CARVALHO, P. S.; RIBON, A. A. Tópicos em Conservação e Manejo do Cerrado: biodiversidade, solos e uso sustentável. Goiânia, Brasil: Kelps, 2019.

MIRANDA, S. DO C. DE; JÚNIOR, M. C. DA S.; DE-CARVALHO, P. S. O Efeito da proteção do fogo na estrutura da vegetação lenhosa de uma área de Cerrado sentido restrito no Brasil Central. Heringeriana, v. 7, n. 1, p. 61-72, 2013.

MIRANDA, S. DO C.; ABREU, C. R. DE; DE-CARVALHO, P. S. As mudanças climáticas no contexto da Educação Ambiental. In: PORTO, M. D.; SANTOS, MI. L. DOS; FERREIRA, J. R. R. (Eds.). . Os desafios do ensino de ciências no século XXI: e a formação de professores para a educação básica. Anápolis - GO: CRV; Ed. Universidade Estadual de Goiás (co-edição), 2016. p. 123-138.

MONTANINI, S. M. P.; MIRANDA, S. DO C. DE; DE-CARVALHO, P. S. O Ensino por Investigação e o Ensino de Botânica na Educação Básica. II Congresso Nacional de Ensino de Ciências e Formaçõ de Professores - II CECIFOP 2019. Anais...Catalão: Universidade Federal de Goiás, Campus Catalão (ISSN: 2526-7485), 2019

MORAES, C. R.; VARELA, S. Motivação do aluno durante o processo de ensino- aprendizagem. Revista Eletrônica de Educação, n. 1, p. 1-15, 2007.

MOREIRA, M. A. Mapas conceituais e diagramas V. Porto Alegre: Instituto de Física, Universidade Federal do Rio Grande do Sul, 2006.

MOREIRA, M. A. Aprendizagem significativa: a teoria e textos complementares. São Paulo: Editora Livraria da Física, 2011a.

MOREIRA, M. A. Aprendizagem Significativa: Um Conceito Subjacente. Aprendizagem Significativa em Revista, v. 1, n. 3, p. 25-46, 2011 b.

MYERS, N. et al. Biodiversity hotspots for conservation priorities. Nature, v. 403, n. 6772, p. 853-8, 24 fev. 2000.

NOVAK, J. D.; GOWIN, B. Aprender a Aprender. [s.I: s.n.].

NOVAK, J. D.; GOWIN, B. D. Aprender a Aprender. [s.I: s.n.]. v. 53

Revbea, São Paulo, V. 14, № 3: 220-237, 2019. 
OLIVEIRA, L. A. et al. Desenvolvimento de uma Sequência Didática sobre Meio Ambiente na perspectiva da Aprendizagem Significativa. Educação Ambiental em Ação, v. 68, n. Junho-Agosto, p. 1-16, 2019.

OLIVEIRA, M. M.; FROTA, P. R. DE O. Mapas Conceituais como estrategias para o Ensino de Educação Ambiental. Atos de Pesquisa em Educação, v. 7, n. 1, p. 228-241, 2012.

RODRIGUES, G. S. et al. O Estado Da Arte Das Práticas Didático-Pedagógicas Em Educação Ambiental (Período De 2010 a 2017) Na Revista Brasileira De Educação Ambiental. Revista Brasileira de Educação Ambiental, v. 14, n. 1, p. 09-28, 2019.

SANTOS, R. D. C. E. DOS; CHIAPETTI, R. J. N. Uma investigação sobre o uso das diversas linguagens no Ensino de Geografia: uma interface Teoria e Prática. Geografia Ensino \& Pesquisa, v. 15, n. 3, p. 167-183, 18 jan. 2011.

SANTOS, G. J. S. et al. Ludicidade em Foco: Interfaces Entre as Teorias de Ausubel e Piaget Aplicadas ao Ensino de Ciências. II Congresso Nacional de Ensino de Ciências e Formaçõ de Professores - II CECIFOP 2019. Anais...Catalão: Universidade Federal de Goiás, Campus Catalão, 2019

SANTOS, G. J. S.; DE-CARVALHO, P. S. A Ludicidade em um Viés Histórico Pedagógico: Desafios e Perspectivas Contemporâneas no Fazer e Ensinar Ciências. Revista Anápolis Digital, v. 7, n. 3, p. 1-11, 2018.

SANTOS, G. J. S.; DE-CARVALHO, P. S.; MIRANDA, S. DO C. DE. A Ludicidade em Ciências: Implicações Didático Pedagógicas no Fazer Docente. In: FERREIRA, G. R. (Ed.). . Educação: Políticas, Estrutura e Organização 8. Ponta Grossa: Atena Editora, 2019. p. 197-204.

SIMON, M. F. et al. Recent assembly of the Cerrado, a neotropical plant diversity hotspot, by in situ evolution of adaptations to fire. Evolution, 2009.

SORRENTINO, M. Reflexões sobre o panorama da Educação Ambiental no ensino formal. In: VIANNA, L. P. (Ed.). Panorama da Educação Ambiental no ensino fundamental. Secretaria de Educação Fundamental. Brasília: MEC/SEF, 2001. p. 39-42.

SOUZA, N. A. DE; BORUCHOVITCH, E. Mapas conceituais: estratégia de ensino/aprendizagem e ferramenta avaliativa. Educação em Revista, v. 26, n. 3, p. 195-217, 2010.

TAVARES, R. Construindo mapas conceituais. Ciências e Cognição, v. 12, p. 72-85, 2007.

TOALDO, L. et al. Mapa conceitual: estratégia para promover a autorregulação da aprendizagem Concept map: strategy to promote the selfregulation learning. p. 119-139, 2018. 